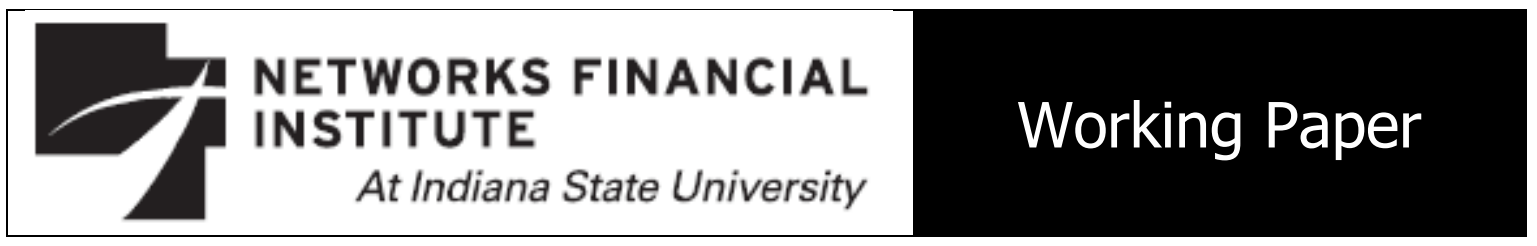

2011-WP-17

July 2011

\title{
The Role of RBC, Hurricane Exposure, Bond Portfolio Duration, and Macroeconomic and Industry-wide Factors in Property-Liability Insolvency Prediction \\ Jiang Cheng and Mary A. Weiss
}

Abstract: This research analyzes the performance of the Risk Based Capital (RBC) ratio and other variables in predicting insolvencies in the property-liability insurance industry during the period 1994 to 2008. This research contributes to the literature by analyzing a longer period of time than previous research, testing timely variables such as exposure to hurricane prone areas and testing the role of macroeconomic and industry-wide variables in property-liability insurer insolvencies. The results indicate that the accuracy of the RBC ratio in predicting insolvencies is inconsistent over time and that some previously tested financial ratios that are part of the Financial Analysis Solvency Tools system do not always reliably predict insurer insolvency. In addition, the insolvency propensity is found to be significantly related to an insurer's hurricane prone area exposure, changes in interest rates, the industry-wide combined ratio, and the industry-wide Herfindahl index of premiums written.

About the Author: Professor Jiang Cheng joined the Scott College of Business at Indiana State University for the 2011 Spring semester as a visiting scholar for Networks Financial Institute. Cheng has taught actuarial science, corporate governance, international corporate finance and economics for several years in the United States and in China. He received B. S. in Economics \& Applied Mathematical Statistics from the Shanghai University of Finance and Economics, and an MBA from Fudan University, China. He earned his Ph.D. degree in Risk Management and Insurance from Temple University at Philadelphia. Professor Cheng's research has been published by leading insurance journals in the United States, such as Journal of Risk and Insurance. He specializes in insurance regulation, corporate governance, financial market and institution, and accounting manipulation. Dr. Mary A. Weiss is Deaver Professor of Risk, Insurance and Healthcare Management at Temple University's Fox School of Business and a Past President of the premier insurance academic organization in the U.S., the American Risk and Insurance Association (ARIA). She is Editor of Risk Management and Insurance Review and an Associate Editor for the Journal of Risk and Insurance. Her research, consisting of more than 30 articles, has focused on financial services conglomeration, efficiency measurement of insurers, no-fault automobile insurance, reinsurance, regulation, and underwriting cycles. She obtained her PhD at the Wharton School of the University of Pennsylvania and has been on the faculty of Temple University since 1986.

Keywords: Risk-Based Capital Ratios, Insolvency, Hurricane Exposure, Duration, Macroeconomic Factors.

The views expressed are those of the individual author and do not necessarily reflect official positions of Networks Financial Institute. Any errors or omissions are the responsibility of the author. Please address questions regarding content to Jiang Cheng at jcheng@sjtu.edu.cn. NFI working papers and other publications are available on NFI's website (www.isunetworks.org). Click "Thought Leadership" and then "Publications/Papers." 


\section{The Role of RBC, Hurricane Exposure, Bond Portfolio Duration, and Macroeconomic and Industry-wide Factors in Property-Liability Insolvency Prediction}

\section{Introduction}

Well-designed solvency surveillance systems can help regulators identify weak insurers so that they can intervene before an insurer's capital becomes inadequate to support operations. State regulators with the support of the National Association of Insurance Commissioners (NAIC) use several mechanisms/tools for this purpose. Two prominent solvency surveillance mechanisms/tools are Risk Based Capital (RBC) requirements and the Financial Analysis Solvency Tools (FAST). These were developed partly as a response to a rash of insolvencies during the 1980s and went into effect in the 1990s.

The RBC requirements that were put into effect in 1994 for the property-liability insurance industry were designed to identify insurers with potentially weak capital positions for regulatory intervention purposes. Risk Based Capital itself is determined from a formula that attaches weights (or factors) to detailed, risk-related items in the insurer's financial statements, and the property-liability RBC formula has changed very little since its inception. ${ }^{1} \quad$ RBC results have sometimes been used as a financial strength or financial solvency indicator in insolvency studies (although it was not originally intended for this purpose), and this strain of the literature has found that RBC results have low accuracy in predicting insurer insolvencies (Cummins, Harrington, and Klein, 1995; Cummins, Grace and Phillips, 1999; and Grace, Harrington, and Klein, 1998).

\footnotetext{
${ }^{1}$ The NAIC RBC Annual Forecasting Kits indicate only small adjustments have been made to the manner in which RBC is calculated in the years since the adoption of the RBC system. The changes in the RBC formula for property-liability insurers have been more a matter of adjusting certain factors based on industry experience rather than fundamental structural changes in the formula. In addition, some phase-ins occurred in the early years of their implementation. See Cummins, Harrington, and Klein (1995) or an RBC Forecasting Kit for more details of the RBC calculation.
} 
The FAST system, implemented in 1993, consists of 29 financial ratios which are analyzed by the NAIC to obtain an insurer's FAST score. The FAST system is more dynamic than RBC requirements in that the financial ratios that comprise FAST may change from year to year. The FAST system employs more sophisticated ratio analysis than the previous Insurance Regulatory Information System (IRIS), which consists of 12 financial ratios (Klein, 1995). Insurers do not know the set of ratios that are used to compute FAST scores, nor the weights that are given to specific financial ratio ranges under FAST. ${ }^{2}$ Cummins, Grace and Phillips (1999) found that a core set of financial ratios used in the FAST system were superior to the RBC ratio in predicting insurer insolvencies in the period 1990 to $1992 .^{3}$

Studies of insurer insolvencies are not limited to the accuracy of the RBC ratio and the FAST scores in predicting insolvencies. A long, rich research history exists concerning property-liability insurer insolvency prediction. Recent examples include Lee and Urrutia (1996), Chen and Wong (2004), Browne and Hoyt (1995), Kim et al. (1995), Brockett et al. (1994) and BarNiv and McDonald (1992). Most of these studies use firmspecific data to predict individual insurer insolvency (e.g., insurer financial information such as financial ratios), while a few use only macroeconomic and insurance industry-

\footnotetext{
${ }^{2}$ The weights given to the financial ratios can vary by year as well.

${ }^{3}$ These are not the only solvency surveillance tools used by regulators. For example, all insurers must be examined by the state at least once every five years and more often if the regulator deems it necessary. The Analyst Team System (ATS) is used also; this is an automated review process using statistical analysis, a scoring system, and RBC to assign review levels for insurers. The end result of the ATS is a national prioritization system for insurers. The NAIC also performs an RBC trend test and uses loss reserve projection tools to analyze reserve adequacy. Insurers appearing to be in poor financial condition as a result of these analyses are further reviewed by experienced analysts to determine the degree of financial distress present. For insurers in financial distress, the results of the latter analysis are then communicated to the state insurance departments in which the insurer is licensed. The NAIC's Financial Analysis Working Group (FAWG) reviews nationally significant insurers every quarter. Any nationally significant insurer deemed to be in financial distress is then prioritized for further analysis. See the exposure draft, The United States Insurance Financial Solvency Framework, for more details of solvency regulation (available from the NAIC's website).
} 
wide variables (e.g., Browne and Hoyt, 1995). However, given changes in the nature of risk exposures in the industry over time (e.g., catastrophes) and the importance of interest rates and investments in the financial health of property-liability insurers, new and untested variables may be important in predicting insurer insolvencies, i.e., exposure to hurricane-prone areas and duration of bond investments.

The purpose of this study is to determine how the RBC system, FAST and additional variables perform in contemporary prediction of insolvency in the propertyliability insurance industry. More specifically, a model of insurer insolvency prediction that combines new firm-specific variables and macroeconomic and industry-wide variables is tested. A secondary purpose is to assess the accuracy of $\mathrm{RBC}$ requirements and the FAST ratios in identifying insolvent insurers over a recent sample period (i.e. 1994 to 2008). ${ }^{4}$ We posit that the ability of RBC requirements and the FAST ratios to predict insurer insolvencies declined over our sample period as the nature of insolvencies changed.

This research contributes to the literature in several ways. First, it integrates RBC, FAST, and other factors to provide a more comprehensive, efficient, and effective model for predicting insurers' solvency. Second, the study uses a large sample of insurers and extends the research period from prior studies. Third, it focuses on classification accuracy by providing an examination of financially distressed insurers with the highest probability of insolvency. Finally it provides potential applications and implications for regulators, insurers and researchers (in the form of future research).

\footnotetext{
${ }^{4}$ Because we investigate insurers prior to insolvency, annual data and ratios up to 2005 are used in the actual analyses and predictions up to 2008 .
} 
This research is important since, in June 2008, the NAIC launched a Solvency Modernization Initiative (SMI) in which the current solvency system is being assessed. Under this initiative, recalibration of $\mathrm{RBC}$ requirements is being considered, among other measures. ${ }^{5}$ Thus, this research is very timely and can be helpful in evaluating the RBC system. Further, it provides insights into financial distress/insolvency prediction by identifying additional variables associated with insolvency.

The research proceeds as follows. First, logistic regression analyses are conducted by year (starting with 1994) to determine the relevance of the RBC ratio and the core set of FAST financial ratios used by Cummins, Grace and Phillips (1999) in predicting insolvencies over time. The solvent insurer sample consists of all NAIC insurers with available data. Then the predictive accuracy of $\mathrm{RBC}$ requirements and the FAST financial ratios are investigated by examining the tradeoffs between Type I and Type II errors. ${ }^{6}$

Next, additional variables, including firm-specific variables and macroeconomic and industry-wide variables, are added to a pooled model used to predict insolvency. The sample used in these regressions is a "nonproportionate" random sample which is drawn in a manner consistent with the methodology in Cummins, Grace, and Phillips (1999). In the latter analysis, nonproportionate sampling data from Cummins, Grace, and Phillips (1999) (from 1990 to 1992) are combined with 1994 to 2008 data to create a longer time series. A longer time series is desirable because the incidence factors expected to be

\footnotetext{
${ }^{5}$ Other measures include considering the use of partial or full internal (dynamic) modeling of insurer operations. Dynamic analysis is already being used for certain life insurance reserves.

${ }^{6}$ The Type I error rate is the proportion of failed insurers that are not predicted to fail. The Type II error rate is the proportion of solvent insurers that are incorrectly predicted to fail.
} 
related to insolvencies fluctuate significantly over time (such as hurricanes and interest rates), and so a long time series is necessary to capture their impact successfully.

By way of preview, the annual multivariate logistic regression results indicate that the inverse RBC ratio is significantly related to insolvency in all years, except 1994. However, it is only weakly significant (i.e., significant at the 10 percent level) in three years. With respect to the FAST variables, the numbers of variables based on the nineteen FAST financial ratios that are significant vary substantially from year to year. In several years, only one FAST related variable is significant. The predictive ability of the inverse RBC models and FAST models fluctuate significantly over time rather than decline steadily. The pooled logistic regression results indicate that insurers writing proportionately more business in hurricane prone states are more likely to become insolvent and that the insolvency propensity is positively related to changes in the interest rate, the industry-wide combined ratio, and the industry-wide Herfindahl index of premiums written.

The remainder of this research proceeds as follows. The next section develops the formal hypotheses to be investigated. This is followed by a section containing the sample and data description. The next section discusses the research method. The succeeding section presents the results. Then additional results and robustness tests are described, with the last section providing conclusions.

\section{Hypotheses Development}

The implementation of $\mathrm{RBC}$ requirements significantly increased the regulatory capital requirements of a property-liability insurer. If there is a regulatory constraint associated with the RBC system on insurers, insurers would have an incentive to adjust 
their capital or operating behavior to avoid regulatory intervention after the RBC requirements were instituted. The latter might be accomplished by making real changes (such as raising new capital if existing capital levels are deemed insufficient by RBC standards) or making illusory changes that improve the $\mathrm{RBC}$ ratio without improving the actual capital position of the company (e.g., manipulation of loss reserves, or exploiting anomalies in the $\mathrm{RBC}$ formula in which the $\mathrm{RBC}$ factor is not commensurate with the risk). ${ }^{7}$ If illusory changes are made then the predictive accuracy of the $\mathrm{RBC}$ ratios would be expected to deteriorate over time. Further, the reasons for insurer insolvencies may change over time and be related to factors that are not reflected in the RBC formula. This would affect the predictive power of RBC over time also. Hence, Hypothesis 1 states, Hypothesis 1: The ability of the RBC ratio to predict property-liability insurer insolvencies declined over the sample period.

The above arguments mostly can also be applied to the core ratios comprising the FAST system, and thus Hypothesis 2 states, ${ }^{8}$ Hypothesis 2: The ability of the core ratios comprising the FAST system to predict property-liability insurer insolvencies declined over the sample period.

Macroeconomic market factors have been identified as being related to insurer overall financial performance in prior studies (e.g., Cummins, 1991 and Grace and Hotchkiss, 1995). Industry performance, too, has been associated with insolvencies (e.g., Browne and Hoyt, 1995; Browne, Carson and Hoyt, 1999; and Chen and Wong, 2004). ${ }^{9}$

\footnotetext{
${ }^{7}$ Existing literature suggests that financially distressed insurers might manipulate their financial statement results to avoid regulatory intervention. For example, troubled insurers have been found to be more likely to underestimate loss reserves relative to other insurers (e.g., Petroni, 1992; Petroni and Beasley, 1996; Beaver, McNichols, and Nelson, 2003; and Gaver and Paterson, 2004).

${ }^{8}$ It is not possible to test the efficacy of the FAST system directly, since all of the ratios and the weights for their ranges are not made public.

${ }^{9}$ A.M. Best (1991) finds that the number of industry insolvencies is correlated with the underwriting cycle and interest rates. But this study does not analyze these factors in a multivariate setting to determine their individual significance in insolvencies.
} 
Thus market conditions that are exogenous to the insurer may affect the insolvency propensity. Other exogenous events may be related to insolvency, too, such as the occurrence of catastrophes. Thus Hypothesis 3 states, Hypothesis 3: Exogenous factors such as macroeconomic conditions, industry-wide performance and catastrophes affect insurer insolvencies.

An important macroeconomic factor is interest rates. If interest rates serve as a proxy for investment earnings on insurers' surplus, they should be negatively related to an insurers' insolvency propensity, everything else held constant. On the other hand, a higher interest rate may be associated with a heavier operating cost burden and a higher required return to capital (Chen and Wong, 2004), making it directly related to insolvency. ${ }^{10}$ Changes in interest rates themselves may be directly related to insolvencies, too, since the market values of bonds decrease as interest rates increase. ${ }^{11}$ Therefore, Hypothesis 3a states, Hypothesis 3a: Interest rate-related variables are significantly related to an insurer's insolvency propensity.

Property-liability insurers' investments consist largely of bonds, and the market values of bonds are significantly related to interest rates and their changes. Bond duration measures the sensitivity of an insurer's bond portfolio to interest rate changes, with higher durations associated with higher volatility or sensitivity. Therefore Hypothesis $3 b$ states,

\footnotetext{
${ }^{10}$ Arguably, insurance managers might be tempted to undertake more risk when interest rates are high to meet the capital hurdle rates (at least for stock companies). Browne, Carson and Hoyt (1999) have a different interpretation for the role of interest rates in life insurer insolvencies. They reason that life insurers are more likely to face disintermediation than property-liability insurers when interest rates rise. This is because policyholders are more likely to withdraw funds from a life insurer when market interest rates exceed the yield rates credited by the insurer on policyholder funds.

${ }^{11}$ Note that reported bond values for financial statement purposes might not be affected by interest rate changes. That is, bond values would be unaffected if bonds are valued at amortized cost.
} 
Hypothesis 3b: An insurer's bond duration, as a measure of interest rate risk, is positively associated with the insolvency propensity.

The property-liability insurance industry undergoes periods of soft and hard markets. Soft (hard) markets are characterized by declining (improving) underwriting profits. Insolvencies are more likely during soft markets, because these are associated with prolonged years of declining profitability and intense price competition (Gron, 1994). ${ }^{12,13}$ As overall profitability in the industry declines (the market softens) more insolvencies occur. Hence Hypothesis 3c states, Hypothesis 3c: The combined ratio, a measure of underwriting profitability, is directly related to insolvency.

The industry Herfindahl-Hirschman Index (HHI) (hereafter herfindahl) of premiums written indicates the distribution of premiums across insurers in the industry and can be interpreted as a measure of competition. Since a low herfindahl index is associated with more intense competition, the herfindahl index might be negatively related to insurer insolvencies. On the other hand, since relatively more insolvencies occur in a soft market, which lasts for several succeeding periods, an argument might be made that the herfindahl index is positively related to insolvency. ${ }^{14}$ Therefore, whether a

\footnotetext{
${ }^{12}$ Underpricing in soft markets also tends to be associated with underreserving (whether it is intentional or not). In addition, insurers are subject to unanticipated inflation in their loss reserves (e.g., claim costs escalate), especially in long-tail lines; and this also contributes to low profits in soft markets.

${ }^{13}$ More precisely, insolvencies occur more often in the later stage of the soft markets. However, some insurers survive longer because they are in relatively better financial condition than those firms becoming insolvent in the soft market. They generally become insolvent in the early stage of the hard market. This further prolongs the hard market in the property-liability insurance industry due to the so-called capacityconstraint theory (Gron, 1994 and Winter, 1994).

${ }^{14}$ That is, if insolvencies have been occurring in the past, then insurers typically exit the market or merge with other, solvent insurers. In either case, the herfindahl index would be expected to increase as a result because the market is becoming more concentrated.
} 
positive or negative relationship exists between the herfindahl and insolvencies is difficult to predict a priori. ${ }^{15}$ Hence Hypothesis $3 \mathrm{~d}$ states, Hypothesis 3d: The herfindahl index (HHI) is significantly related to insurer insolvencies.

$\mathrm{RBC}$ requirements do not include a factor for catastrophes (although one is currently being developed). ${ }^{16}$ Recently, one type of catastrophe has received considerable interest and concern -- exposure to hurricanes. Therefore, Hypothesis $3 \mathrm{e}$ states,

Hypothesis 3e: Insurers with high exposure to hurricane prone areas are more likely to become insolvent.

\section{Data and Sample}

In this section the samples used in the analysis are described. These consist of annual samples and a sample of observations pooled across years. Following this, the data are described.

\section{Samples}

Annual Multivariate Analysis Sample. An insurer is defined as insolvent in the year it receives its first regulatory action (Cummins, Grace and Phillips, 1999; Cummins, Harrington and Klein, 1995; and Grace, Harrington and Klein, 1998). A three year

\footnotetext{
15 Preceding studies also employ the number of insurers to proxy for competition (Browne and Hoyt, 1995; Browne, Carson and Hoyt, 1999; and Chen and Wong, 2004). The insurer's insolvency propensity is hypothesized to be positively related to the number of insurers. We use the number of insurers as a robustness test in all models estimated and find that the number of insurers has a positive relation with the insurer's insolvency propensity. The number of insurers is highly correlated with the herfindahl. We use the herfindahl rather than the number of insurers because the herfindahl is more often used to proxy for competition in the economics literature.

${ }^{16}$ The NAIC began designing the risk based factor formula in 1990, prior to major hurricanes. In addition, regulators discussed but did not include a catastrophe component to the property-liability RBC formula when it was being developed. (There was strong industry resistance to including a catastrophe component.) Regulators also discussed including a size component and a dynamic component as recommended by the American Association of Insurers.
} 
prediction horizon is used to determine the insolvent insurer sample. That is, the insolvent insurer sample used in this part of the analysis consists of insurers that became insolvent one, two, or three years prior to insolvency. Thus if an insurer received its first regulatory action in 1999, then the insurer is included in the annual regression analysis in 1998 (one year prior to insolvency), in 1997, (two years prior to insolvency) and in the annual regression sample for 1996 (three years prior to insolvency). ${ }^{17}$ The one to three year window period is selected to be consistent with Cummins, Grace, and Phillips (1999) and to guarantee that a sufficient sample of insolvent insurers exists in each year. ${ }^{18}$ The solvent insurer sample consists of all insurers with the necessary data (as explained below under Data).

Pooled Multivariate Sample. For the pooled data analysis, concerns about having an adequate number of insolvent insurers for the analysis or comparability with prior studies do not apply. Therefore, the insolvent insurer sample used in the pooled analysis consists only of insurers two years prior to becoming insolvent. For example, if an insurer became insolvent in 1999, then that firm would be treated as insolvent in the insolvent insurer sample for 1997 for the pooled analysis, and the insurer would be excluded from all other sample years. A two-year prediction period was chosen because it would provide information to regulators well ahead of insolvency while still being able to find relationships between the insolvency and variables associated with insolvency. ${ }^{19}$

\footnotetext{
${ }^{17}$ An insurer is never included more than once in an annual insolvent insurer sample.

${ }^{18}$ Although it might be considered desirable to test samples in which only insurers one year prior to insolvency or insurers two years prior to insolvency only are included in each annual sample, the number of insolvencies was too small in some years to estimate the annual regression models using this approach.

${ }^{19}$ Data for insolvencies that occurred one year after the sample period were missing for a large number of insurers, hence it was not used.
} 
In the pooled analysis, the years 1990 to 1992 are added to the sample to increase the time series studied. The data for 1990 to 1992 are the same as used in Cummins, Grace, and Phillips (1999) and are described there. Cummins, Grace, and Phillips (1999) used nonproportionate matching samples of insolvent and solvent insurers over the periods 1990 to 1992 in their analysis. Therefore, the nonproportionate random sampling approach used in Cummins, Grace, and Phillips (1999) is used to construct the solvent insurer samples for the years in our sample, 1994 to $2005 .^{20}$ That is, a random sample of 300 solvent insurers with positive premiums, surplus, and assets was drawn for each sample year. ${ }^{21}$ The sampling techniques make the samples for 1990 to 1992 and 1994 to 2005 consistent with each other. ${ }^{22}$

The numbers of solvent and insolvent insurers by year are presented in Table 1. The numbers of insolvent insurers by year are contained in the column entitled, "No. of Insolvencies from $t+1$ to $t+3$." Table 1 indicates that the maximum number of insolvent insurers using the three year prediction horizon is 89 in 1999 and the minimum is 19 in 2005. In the pooled regressions, the numbers of insolvent insurers for the regression (1990-1999) and holdout sample (2000-2005) can be found in the column titled, "No. of Insolvencies in $\mathrm{t}+2 . "$ The solvent insurer sample varies from a minimum of 1687 in 1994 to a maximum of 1910 in 1996.

\footnotetext{
${ }^{20}$ Although many previous studies have employed a choice-based equal-matching sampling process (see e.g., Trieschman and Pinches, 1973 and Lee and Urrutia, 1996), other studies argue that this method might lead to oversampling of insolvent firms and biased and inconsistent estimates (see e.g., Palepu, 1986; BarNiv and McDonald, 1992; and Kim et al., 1995).

${ }^{21}$ The samples of solvent insurers vary by year. In addition, insurers with an organizational form other than stock or mutual were deleted from the data before drawing the random sample. Once the solvent insurer sample was drawn, insurers with missing RBC were deleted, so that the sample of solvent insurers used in the analysis is less than 300 each year.

${ }^{22}$ Comparison of the sample of solvent insurers with industry-wide data indicates that the sample is representative of the industry. Means, standard deviations, and medians for assets, surplus, premiums earned, net premiums written, company type, loss ratio, and the RBC ratio are compared for the solvent insurer sample and the industry. The results indicate no significant difference in these statistics for the sample of solvent insurers used here versus the industry.
} 


\section{Data}

Data for the individual sample insurers were obtained primarily from the insurers'

Annual Statements and is at the firm level. Thus only insurers with RBC ratio data are eligible to be included in the samples. ${ }^{23}$ Insolvent insurers were identified from A.M. Best Company lists of single and multi-state insurer insolvencies, ${ }^{24,25}$ except that the insolvent insurers identified for 1990 to 1992 are the same as used by Cummins, Grace, and Phillips (1999). ${ }^{26}$ Several insolvent insurers are excluded from the sample because they did not file financial reports with the NAIC and do not appear in the NAIC Annual Statement database as a result. ${ }^{27}$

Data for the macroeconomic variables were obtained from several sources. The interest rate variable is the average "Moody's Yield on Seasoned Corporate Bonds-All Industries, AAA" for the three years preceding year $\mathrm{t}$ and was obtained from the Board of Governors of the Federal Reserve System. A three year period is selected based on asset duration measures provided in Staking and Babbel (1995). ${ }^{28}$ The change in interest rate

\footnotetext{
${ }^{23} \mathrm{RBC}$ ratios are unavailable for certain specialty insurers and insurers that did not file a statement with the NAIC.

${ }^{24}$ The first regulatory action includes proceedings associated with conservation of assets, rehabilitation, receivership, or liquidation.

${ }^{25}$ Although Cummins, Grace, and Phillips (1999) identified insolvent insurers using NAIC Contact Person Reports, we did not have access to these. Therefore, insolvent insurers were identified using A.M. Best company information. However, the list of insolvent insurers identified in this study from A.M. Best Company information for 1991 to 1995 was virtually identical with the list of insolvent insurers identified by Cummins, Grace, and Phillips (1999) for 1991 to 1995 . The solvent insurer sample used by Cummins, Grace, and Phillips (1999) had varying numbers of solvent insurers across the years, but the average was about 250 .

${ }^{26}$ The authors are grateful to J. David Cummins for making the data for 1990 to 1992 available to them. Note that RBC ratios are not available from insurers' Annual Statements prior to 1994, hence 1993 could not be included in our sample period.

${ }^{27}$ Insurers that are not included in the NAIC database are typically single-state insurers and were likely to have been excused by a state regulator from filing an Annual Statement because they had few assets and/or liabilities, were undergoing liquidation, or were in the process of being sold (Cummins, Grace, and Phillips, 1999).

${ }^{28}$ The AAA bond yield is chosen because it is highly correlated with overall yields on insurers' investment portfolios, which are heavily weighted toward high-grade bonds and Treasury bills. The market yield on
} 
is calculated as the average change for the four quarters in year $\mathrm{t}-3$ of the market yield on U.S. Treasury securities with three months to maturity, and these data were obtained from the Board of Governors of the Federal Reserve System. Finally, data for the industrywide combined ratio were obtained from A.M. Best Co., Best's Aggregates \& Averages, various years.

\section{Research Method}

The empirical research consists of multivariate analyses of the predictive power of the variables described in the hypotheses for identifying insurers that become insolvent. Annual logistic regressions are used alternatively to determine whether the $\mathrm{RBC}$ ratio and a core set of FAST financial ratios are significant predictors of insolvency during the sample period and whether the predictive power of the $\mathrm{RBC}$ ratio and a core set of FAST financial ratios declined over time..$^{29}$ Then additional logistic regression analysis is conducted in which firm-specific, industry-wide, and macroeconomic variables are added as independent variables to a pooled model. The remainder of this section describes the analyses in more detail.

\section{Annual Multivariate Analysis}

\footnotetext{
U.S. Treasury securities with three months to maturity was tested also as a robustness test, and the results were similar when the alternative variable was used.

${ }^{29} \mathrm{We}$ do not compare all of the different econometric approaches that have been used as predictive models in this paper, as one goal is to compare our results with recent prior studies. That is, numerous prediction methods have been employed in insurer insolvency studies, including multiple discriminant analysis (Trieschmann and Pinches, 1973 and Ambrose and Seward, 1988), regression analysis (Harrington and Nelson, 1986), mean-variance analysis (BarNiv and Smith, 1987), neural network (Brockett et al., 1994 and Brockett et al., 2006), event history analysis (Kim et al., 1995), and logit and probit models (Barniv, 1990; BarNiv and Hershbarger, 1990; Cummins, Harrington and Klein, 1995; Lee and Urrutia, 1996; Grace, Harrington and Klein, 1998; and Cummins, Grace and Phillips, 1999). BarNiv and McDonald (1992) review the methodological issues in identifying financial distress in the insurance industry.
} 
The multivariate analysis of the annual data relies on multivariate logistic regression taking the following form:

$$
\begin{aligned}
Y_{j t}=\alpha_{0}+ & \beta_{1}(\text { Inverse RBC ratio })_{j, t-i}+\beta_{2} \log (\text { Net Premiums Written })_{\mathrm{j}, \mathrm{t}-\mathrm{i}}+\beta_{3} \text { (Mutual } \\
\text { dummy })_{\mathrm{j}, \mathrm{t}-\mathrm{i}}+\varepsilon_{\mathrm{j} t} &
\end{aligned}
$$

where (Inverse $\mathrm{RBC}$ ratio) j,t-i $_{\text {in }}$ is the ratio of $\mathrm{RBC}$ to Total Adjusted Capital for insurer $\mathrm{j}$ in year $\mathrm{t}-\mathrm{i}$; (Net Premiums Written $)_{\mathrm{j}, \mathrm{t}-\mathrm{i}}$ is net premiums written for insurer $\mathrm{j}$ in year $\mathrm{t}-\mathrm{i}$; the mutual dummy is equal to one if insurer $\mathrm{j}$ is a mutual in year $\mathrm{t}-\mathrm{i}$ and zero otherwise; and $\varepsilon_{\mathrm{jt}}$ is a mean-zero random error term that is assumed to follow the logistic distribution. For insolvent insurers, the subscript $i$ denotes the number of years prior to year $t$ that the insurer becomes insolvent (i.e., one to three years); i is equal to 3 for solvent insurers. The dependent variable $\mathrm{Y}_{\mathrm{jt}}$ is the unobservable propensity for the insurer to fail within three years subsequent to year $\mathrm{t}-3$. It is set equal to one if the insurer failed within the three year prediction period, and zero otherwise. ${ }^{30,31}$

The additional control variables included in equation (1) are the same as those used by Cummins, Harrington, and Klein (1995) and Cummins, Grace, and Phillips (1999). The exception is with respect to the size variable - net premiums written is considered to be a better measure of size in property-liability insurers than assets, hence net premiums written is used as the size variable. Prior studies indicate that smaller firms have a higher risk of insolvency than larger insurers, so the expected sign for the

\footnotetext{
${ }^{30}$ More specifically, if the insurer failed one year prior to year $t$, then the independent variables reflect data for $t-1$. If the insurer failed two years prior to year $t$, then the independent variables reflect data for $t-2$. If the insurer failed three years prior to year $t$, then the independent variables reflect data for $t-3$.

${ }^{31}$ The numbers of insolvent insurers by year are too small to be able to use a holdout sample.
} 
coefficient of $\log$ (Net Premiums Written) is negative. ${ }^{32}$ Mutual and stock insurers have different company structures and operating characteristics (e.g., Mayers and Smith, 1981, 1988, and Lamm-Tennant and Starks, 1993). ${ }^{33}$ Prior studies indicate that mutuals have a lower insolvency propensity; hence the expected sign for this variable is negative also.

Equation (1) is estimated separately for each year of the sample period and Type I and Type II errors are calculated. A positive and significant coefficient for the inverse of the RBC ratio would signify that an insurer's insolvency propensity increases as its required capital increases relative to its actual (adjusted) capital and that the RBC ratio is a significant predictor of insolvency. If the significance of the RBC ratio declines over time and/or the prediction accuracy of the logistic model declines over time (in terms of Type I and II errors), then Hypothesis 1 would be supported.

Equation (1) is also estimated separately for each year over our sample period after replacing the inverse $\mathrm{RBC}$ ratio with the core set of FAST financial ratios used by Cummins, Grace, and Phillips (1999). The nineteen FAST financial ratios are listed in Appendix 1. Cummins, Grace, and Phillips (1999) found a high degree of multicollinearity among the FAST ratios; therefore, they used factor analysis on the nineteen ratios, and factors with an eigenvalue greater than one were used as independent variables in the logistic model (rather than all nineteen financial ratios). The same approach is used in this study. ${ }^{34}$

\footnotetext{
${ }^{32}$ The franchise values of small insurers are lower than for larger insurers, and thus smaller insurers have less incentive to reduce insolvency risk. In addition, small insurers tend to have more volatility in claim costs and operating income.

${ }^{33}$ For example, Lamm-Tennant and Starks (1993) argue that mutuals may specialize in the sale of less risky coverage in a given line of business than stocks.

${ }^{34}$ To eliminate multicollinearity among the factors, the factors are orthogonalized before their use (i.e., varimax rotation is used). Following Cummins, Grace, and Phillips (1999), "the set of factors included in the final version of the logistic model is further reduced by eliminating factors that were not statistically significant in earlier runs. Factors were eliminated one at a time with the least significant eliminated first."
} 
Recall that Hypothesis 2 indicates that the predictive accuracy of these core FAST variables should decline over time. Hence, if the significance of the FAST financial factors declines and /or the Type I/II error tradeoffs decline over time, then Hypothesis 2 would be supported.

\section{Pooled Multivariate Analysis}

The pooled regression model includes an expanded set of variables. These variables include the industry-wide performance ratios, interest rate variables, the duration of an insurer's bond portfolio, and an insurer's exposure to hurricane-prone states. The benefit of conducting the pooled analysis is that it allows for testing of variables that do not vary by year such as the macroeconomic and industry-wide variables and the number of degrees of freedom in the model is increased.

The model estimated is

$$
\begin{aligned}
& \mathrm{Z}_{\mathrm{jt}}=\alpha_{0}+\delta_{1}(\text { Inverse RBC ratio })_{\mathrm{j}, \mathrm{t}-2} \\
& +\lambda_{1} \log (\text { Net Premiums Written })_{\mathrm{j}, \mathrm{t}-2}+\lambda_{2}(\text { Mutual dummy })_{\mathrm{j}, \mathrm{t}-2} \\
& +\lambda_{3}(\text { Bond Portfolio Duration })_{\mathrm{j}, \mathrm{t}-2} \\
& +\lambda_{4}(\text { Gulf and south Atlantic State Hurricane Exposure })_{\mathrm{j}, \mathrm{t}-2} \\
& +\lambda_{5}(\text { North and mid-Atlantic State Hurricane Exposure })_{\mathrm{j}, \mathrm{t}-2} \\
& +\beta_{1}(\text { FAST Financial Ratios })_{\mathrm{j}, \mathrm{t}-2} \\
& +\gamma_{1}(\text { Herfindahl Index of Premiums Written })_{\mathrm{t}-2} \\
& +\gamma_{2}(\text { Industry-wide Combined Ratio })_{\mathrm{t}-2} \\
& +\gamma_{3}(\text { Overall Interest Rate })_{\mathrm{t}-2} \\
& +\gamma_{4}(\text { Interest Rate Change })_{\mathrm{t}-2}+\omega_{\mathrm{j} t},
\end{aligned}
$$


The parameters are $\alpha_{0}, \delta_{\mathrm{n}}, \lambda_{\mathrm{p}}$, and $\gamma_{\mathrm{q}}$, while $\beta_{1}$ is a vector of parameters. The term $\omega_{\mathrm{jt}}$ is a mean-zero random error term assumed to follow the logistic distribution. The remaining subscripts are defined as before, and $\mathrm{Z}_{\mathrm{jt}}$ is defined as one if the insurer becomes insolvent in two years, and 0 otherwise. The model is estimated over the period 1990 to 1999, and the years 2000 to 2005 are used as a holdout sample. The remainder of this section describes the new model variables in equation (2) in more detail.

The combined ratio, herfindahl index of premiums written, the overall interest rate, and change in the interest rate are included in the model to test Hypotheses $3 \mathrm{a}, 3 \mathrm{c}$, and $3 \mathrm{~d}$. According to Hypotheses $3 \mathrm{a}$ and $3 \mathrm{c}$, the combined ratio and change in interest rate variable should be positively related to the insolvency propensity. The expected signs for the interest rate and herfindahl index are difficult to predict a priori, as explained earlier. Thus interest rates and the herfindahl index are expected to be significantly associated with the insolvency propensity with no expected sign.

Bond duration is included in the model to test Hypothesis 3b. An insurer's bond duration, as a measure of interest rate risk, is expected to have a positive coefficient in the model.

A variable designed to capture an insurer's exposure to hurricane prone areas, the proportion of direct premiums written in hurricane-prone areas, is included in the model to test Hypothesis $3 e^{35}$ Hurricane prone areas are defined for purposes of this study as all states with a coast on the Gulf of Mexico or the Atlantic Ocean. Hurricane-prone areas are further subdivided into two areas. The first hurricane prone area variable reflects the proportion of total direct premiums written in Gulf and south Atlantic states, while the

\footnotetext{
${ }^{35}$ As an alternative, the proportion of an insurer's total premiums written in homeowners insurance in hurricane-prone areas was tested. However, this variable did not perform well, as some insurers that did not write homeowners insurance wrote commercial property insurance.
} 
other measures the proportion of total direct premiums written in north and mid-Atlantic states. $^{36}$ The expected signs for these variables are positive. ${ }^{37}$

\section{Results}

Table 2 provides summary statistics for all variables used in the logistic analyses for the solvent and insolvent insurer samples; the results of t-tests for equality of means for the solvent and insolvent insurer samples are provided as well. Overall, the average inverse RBC ratio is larger for insolvent insurers. ${ }^{38}$ Insolvent insurers are smaller in size (as measured by net premiums written), are less likely to be mutuals, write more business in hurricane-prone states and have shorter bond portfolio durations. Appendix 2 provides a correlation matrix for these variables.

The distribution of the RBC ratios for the insolvent and solvent insurer samples, by year, are presented in Table 3. Cumulative percentages of the percent of insurers with the RBC ratio less than some stipulated level are provided. ${ }^{39}$ Consistent with Cummins, Harrington, and Klein (1995), the percentage of surviving insurers that have RBC ratios less than or equal to 200 percent (i.e., the Company Action Level) is significantly less than 5 percent for the 12 -year sample period. The fact that this percentage is low

\footnotetext{
${ }^{36}$ The Gulf states include Texas, Louisiana, Mississippi, Alabama and Florida. The south Atlantic states include Florida, Georgia, South Carolina, and North Carolina. The mid-Atlantic states include Delaware, New Jersey, Maryland; and the north Atlantic states include Rhode Island, Massachusetts, and Maine. The authors are grateful to J. David Cummins for the suggestion to make a distinction between the two hurricane prone geographic areas. It can be argued that hurricane prone states are all states with Atlantic or Gulf Coast exposure, i.e., all the way around the coast from Texas to Maine. However, the Gulf Coast and south Atlantic states are more exposed than the mid-Atlantic and north Atlantic states.

${ }^{37}$ Loss reserve development may also be a significant insolvency predictor, but it is highly correlated with ratios used in the FAST analysis such as proportion of premiums written in long-tail lines. Thus this variable was not included in the analysis.

${ }^{38}$ Statistical tests strongly reject the null hypothesis of identical distributions or equal proportions for the inverse RBC ratio for solvent and insolvent insurers for each sample year except 1994.

39 The ratios for years prior to 1996 are not perfectly comparable to the ratios for later years because of phase-in aspects of the RBC formula. In 1994 and 1995, the Authorized Control Level (ACL) RBC was set at 0.40 and 0.45, respectively, of the Risk Based Capital after Covariance (Adjustment). Beginning in 1996, the ACL RBC is equal to one-half of the Risk Based Capital after Covariance (Adjustment) (NAIC Research Quarterly, Winter 2000, Vol. 6, Issue 4).
} 
suggests that any regulatory cost associated with the effect of $\mathrm{RBC}$ requirements on sound insurers is relatively low. However, there are on average only about 28 percent of insolvent insurers that have RBC ratios at or below the Company Action Level (i.e., 200 percent). ${ }^{40}$ The relatively low percentage of insolvent insurers with RBC ratios below the minimum action thresholds would seem to suggest that the thresholds are too low to identify insurers that will become insolvent. Klein and Wang (2009) note that making the $\mathrm{RBC}$ requirements more stringent increases the probability of Type I errors and that this problem is exacerbated by the imprecision of the current RBC formula.

Interestingly, the distributions of $\mathrm{RBC}$ ratios in Table 3 indicate that this ratio is particularly ineffective in distinguishing between insolvent and solvent insurers for 1994 . That is, none of the insurers that subsequently became insolvent had $\mathrm{RBC}$ ratios below the Regulatory Action Control Level (TAC/RBC $\leq 150$ percent) in this year. The reason for this is not known, but one explanation is that insurers adjusted their operations prior to the implementation of $\mathrm{RBC}$ requirements to improve their $\mathrm{RBC}$ ratio; another explanation is that some insurers manipulated their financial results so as to improve the reported $\mathrm{RBC}$ ratio. Of course, other explanations are possible, such as the effect of industry market conditions during this year. The remainder of this section contains discussions of the results for the multivariate analyses.

\section{Annual Logistic Regression Results}

\footnotetext{
${ }^{40}$ To obtain the 28.10 percent average, the number of insolvent insurers with RBC ratios less than or equal to 200 percent are added across all years, and the total is divided by the total number of insolvent insurers in the sample. Using the same methodology, the percentages of insolvent insurers with RBC ratios less than or equal to 150 percent (Regulatory Action Level), 100 percent (Authorized Control Level), and 70 percent (Mandatory Control Level) are even lower: 19.31, 12.05, and 10.33 percents, respectively.
} 
The logistic regression results by year corresponding to equation (1) are provided in Table $4 .^{41}$ The significance of the Inverse RBC coefficients, the Type I/ Type II error rate tradeoffs and Maximum-rescaled R-squareds (which are based on the likelihood ratio indexes) are used to gauge the differences in predictive accuracy for the models in each year. $^{42}$

The estimated coefficients for the inverse RBC ratios for the post 1993 period are strongly significant (i.e., significant at the 1 percent level) in only eight of the twelve years after 1993. However, no (declining) trend in the significances of the RBC coefficients exists. Rather, the weakly significant RBC coefficients (i.e., coefficients significant at the 10 percent level) are interspersed throughout the period. These results do not support Hypothesis 1 which states the predictive ability of the RBC rates has declined over time.

With respect to the other coefficients in Table 4, the coefficient for the company size variable is negative and significant about half of the time in the post 1993 period. $^{43}$ It is significant in seven of the twelve years, while the mutual dummy variable is mostly insignificant. There is no clear reason for this, except perhaps that the causes of insolvencies after 1994 are different from the pre-1993 period.

The Maximum-rescaled R-squareds show somewhat of a deteriorating trend over the period 1995 to 2003 overall (with the exceptions of 1999-2000), with Maximum-

\footnotetext{
${ }^{41}$ The Inverse RBC Ratio is winsorized at the 1 and 99 percent level to reduce the influence of a few, very large outliers. This methodology is commonly used in the finance and insurance literature (e.g., Flannery and Rangan, 2006; Minton, Sanders and Strahan, 2004; and Gatev and Strahan, 2006).

${ }^{42}$ Logistic regression maximum likelihood techniques do not generate standard measures of goodness of fit. The Maximum-rescaled R-squared measures the gain in information from running a model with all of the independent variables over a model with the intercept only (see Greene, 2000). The Maximum-rescaled $\mathrm{R}$-squareds appear to be rather high during the last two sample periods, probably due to the fact that the numbers of insolvencies were very small in these years.

${ }^{43}$ Results are similar when $\log$ (Assets) is substituted for $\log$ (NPW).
} 
rescaled R-squareds varying from 0.1188 to 0.0103 over this subperiod. ${ }^{44}$ The Maximum-rescaled R-squareds are very low in almost half of the sample period (i.e., approximately $5 \%$ or below). And the fit of the model is particularly poor over the years 2001 to 2003. Overall, these results provide very limited support for Hypothesis 1 . In fact, the Maximum-rescaled R-squared is high for the year 2005; but, the number of insolvencies in this year is relatively low compared to the other years. ${ }^{45}$

Panel B of Table 4 contains the within-sample Type I error rates for various levels of Type II error rates corresponding to the predictions from the logistic regressions. These error rates are estimated using approximate jackknife fitted values (Pregibon, 1981).

The Type I/Type II error rate tradeoffs decline somewhat over the period 1997 to about 2004. For example, a Type II error rate of 15 percent is associated with a Type 1 error rate of 21 percent in 1996, while Type I error rates of more than 21 percent are associated with a 15 percent Type II error rate for the years 1997 to 2004 . And, in particular, in five of the eight years from 1997 to 2004, a Type 1 error rate of over 50 percent is associated with a Type II error rate of 15 percent. As was the case for the logistic regressions, the Type I/Type II error rate tradeoffs are particularly poor in the year after RBC implementation (1994), and they are relatively good for the period 2005.

\footnotetext{
${ }^{44}$ Maximum-rescaled R-squareds are somewhat larger for 1999-2000.

${ }^{45}$ We contacted the NAIC to double-check that no significant changes in the RBC formula occurred at this time. While there was no significant change in the RBC formula, an RBC trend test was instituted in 2005. But the latter should not have affected the RBC results. In addition, beginning in 2001, changes began to occur regarding what was included in the Actuarial Opinion and who the Actuarial Opinion was reported to (i.e., the Board of Directors). As a result of all of the changes, the reserving process may have become more standardized and refined, most likely having an effect on the quality of reserving estimates. Note that the RBC formula cannot detect underreserving (in particular), so improvements in the quality of the reserving estimates may have improved the quality of the RBC estimate even though it would not affect the $\mathrm{RBC}$ formula itself.
} 
There are no obvious reasons for these results, except that there were relatively fewer insolvencies in these periods, especially in 2005.

Overall, the Inverse RBC results taken together do not provide convincing support for Hypothesis 1. The results do indicate that the predictive ability of RBC fluctuates significantly over time.

Table 5 presents the logistic regression results after replacing the $\mathrm{RBC}$ ratio with factors based on nineteen financial ratios used in the FAST system. ${ }^{46}$ The coefficients for $\log ($ Net Premiums Written) are negative in all years and significant in most years. And, the mutual dummy variable is mostly insignificant. The number of significant FAST Factors varies from year to year, reinforcing the notion that the nature and causes of insolvencies can vary from year to year. The maximum numbers of FAST Factors appear in the equations for 1997 to 2001 (i.e., 5 FAST Factors). Only 1 FAST Factor is marginally significant in the results for 2003 and 2004. Interestingly, no FAST Factors are significant in the year 2005. However, the numbers of insolvencies included in the 2004 to 2005 regressions are very small, hence little weight should be attached to these results.

The Maximum-rescaled R-squareds appear to increase slightly from 1994 to 1996. After 1996, they tend to remain steady or deteriorate somewhat (the results for 2000 and 2002 are exceptions). These results overall do not support Hypothesis 2, which states the predictive power of the FAST Factors declines over time.

The insolvency predictive power of the FAST variables measured in terms of the Type I/Type II error rate tradeoff varies significantly among the years, with even less

\footnotetext{
${ }^{46}$ The number of observations and number of insolvent firms are somewhat different from regressions using the Inverse RBC Ratio only due to missing variables needed for the FAST analysis.
} 
evidence of a trend compared to the results for the inverse RBC ratio. However, the error rate tradeoffs appear to be high. For example, a Type II error rate percent of 15 percent is associated with Type I error rates of more than 40 percent in six of the eleven years from 1994 to 2004. Further, the FAST Factors do not necessarily produce results that are much better than the RBC ratio for low Type II error rates (e.g., 1996 and 2004). In conclusion, the predictive ability of the FAST Factors fluctuates over time rather than declines, and these results do not support Hypothesis 2.

Of course, caution must be used not to read too much into these results as they relate to the FAST system overall. That is, a total of twenty-nine ratios are used in the FAST system to obtain a FAST score, and our results apply only to a subset of the FAST financial ratios. Nevertheless, it is still interesting to note that the predictive accuracy of the FAST factors can vary significantly from year to year.

\section{Pooled Logistic Results}

Table 6, Panel A provides regression results after pooling the observations. The Inverse $\mathrm{RBC}$ ratio is positively and significantly related to insolvency, while insurer size and the mutual dummy variable are negatively and significantly related to insolvency, as expected. Three FAST factors are significant in the model in Table 6. The remainder of this section discusses the results with respect to the new variables added in Table 6 and goodness of fit for the model.

The coefficients for both hurricane risk variables are positive as expected, but only the coefficient for the hurricane high risk variable is significant. Thus, Hypothesis $3 e$ is partly supported. The coefficient for the duration variable is insignificant, and this 
result does not support Hypothesis $3 b$. While the reason for this is not clear perhaps it may mean that insurers protect their bond portfolios from interest rate increases through derivatives or other products; or this result may be due to the fact that over this time period there were several periods of rather small interest rate declines (rather than interest rate increases). ${ }^{47}$

Most of the macroeconomic and industry performance variables are significant in Table 6. The coefficients for the industry-wide combined ratio and change in the interest rate are positive and significant as expected, supporting Hypotheses $3 \mathrm{a}$ and $3 \mathrm{c}$. Thus positive changes in the interest rate decrease the market value of fixed rate bonds and are positively associated with the chance of insolvency. The positive and significant coefficient for the herfindahl index of premiums written indicates that there are more insurer insolvencies when the market is in the "crisis" phase of the cycle when supply of insurance is relatively low (i.e., the market is more concentrated and the herfindahl index increases). This is consistent with Gron (1994) and supports Hypothesis 3d. The interest rate level variable is insignificant in Table 6. With respect to the results overall, Hypotheses 3a, 3c, and 3d are supported, since three of the four interest-related and industry performance variables are significant in the model.

Type I and Type II error rate tradeoffs must be examined for the model in Table 6 and the holdout sample (2000-2005) to determine prediction ability. The holdout sample results are consistent with the Type I/Type II error tradeoffs for the model results reported in Table 6 for (1990-1999). Thus the model in Table 6 is valid. Overall, the Type I/Type II tradeoffs reported in Table 6 are on par with or are better than the

\footnotetext{
${ }^{47}$ For example, Flannery (1981) indicates that commercial banks attempt to foresee trends in the interest rate and arrange asset and liability portfolios with similar average maturities.
} 
tradeoffs reported in Tables 4 and 5, especially for the higher Type II errors. For example, a 20 percent Type II error is associated with a 17 percent Type I error in the holdout sample for Table 6. On average for Tables 4 and 5, the Type I error rate associated with a 20 percent Type II error is 45 and 31 percent, respectively. Nevertheless, the Type I/ Type II error rate tradeoff reported in Panel B of Table 6 might be considered high if this model were used in practice.

\section{Additional Results and Robustness Tests}

The results reported in Tables 4 and 5 are not strictly comparable to prior research due to the sampling methodology. To ensure that our sampling approach is not driving the results observed, we conducted additional analysis using the same sampling techniques as Cummins, Grace, and Phillips (1999) and Grace, Harrington, and Klein (1998) (i.e., nonproportionate sampling). ${ }^{48}$ Robustness tests were carried out also by calculating expected costs of misclassification (ECM) for the results in Tables 4, 5, and 6 . Further, robustness analysis was conducted to ensure that the nonproportionate sample used in Table 6 is representative of the industry. The remainder of this section discusses the additional results and the robustness tests.

\section{Additional Results}

In the annual logistic regressions using nonproportionate matching samples of insolvent and solvent insurers, the estimated coefficients for the inverse $\mathrm{RBC}$ ratios are significant in only seven of the twelve years from 1994 to 2005; the inverse RBC ratio is insignificant in the years 1994, 1998, and 2001 to 2003. The Maximum-rescaled Rsquareds show somewhat of a deteriorating trend from 1995 to 2003 (with the exception of the year 2000), with values ranging from 0.217 to 0.023 in 2003 . However, the

\footnotetext{
${ }^{48}$ Nonproportionate sampling results are available from an authors' appendix.
} 
Maximum-rescaled R-squared jumps to 0.391 in the year 2000. In terms of Type I/Type II error tradeoffs, the error rates show a general deteriorating trend over the period 1996 to 2003 (with the exception of 2000). For example, a Type II error rate of 15 percent is associated with a Type I error rate of 24 percent in 1996, and Type I error rates associated with a Type II error rate of 15 percent exceed 24 percent from 1997 to $2004 .{ }^{49}$ Thus these results are consistent with the results reported in Table 4 in that they show significant fluctuation from year to year rather than a clear trend.

An analysis analogous to that in Table 5 was carried out with the nonproportionate sample used above. Similar to the analysis in Table 5, the numbers of FAST Factors in the analysis vary by year, with only one FAST Factor marginally significant for 1998. The Maximum-rescaled R-squareds fluctuate significantly from year to year with no deteriorating trend evident. Consistent with Table 5, the insolvency predictive power of the FAST variables measured in terms of the Type I/Type II error rate tradeoff varies significantly among the years displaying results similar to the $\mathrm{RBC}$ results in some years. ${ }^{50}$ The Type I/II error rate tradeoffs are high, although not as high as for the $\mathrm{RBC}$ results in most years. For example a Type II error rate of 15 percent is

\footnotetext{
${ }^{49}$ Interestingly, there does appear to be a general fall-off in predictive ability of the RBC models in the post 1993 period compared to the 1990 to 1992 results reported in Cummins, Grace, and Phillips (1999). For example, the average Maximum-rescaled R-squared in the post 1993 period is approximately 15.6 percent compared to 22 percent in the pre-1993 period. In addition, Type I/Type II error tradeoffs deteriorated significantly from the pre 1993 period to the post 1994 period, especially with respect to high Type II error rates. For example, Type II error rates of less than 20 percent would be needed to achieve Type I error rates of less than 50 percent for years before 1994. However, beginning with 1994, Type II error rates of more than 20 percent would be needed for 1994, 1998, and 2001-2003 to achieve Type I error rates less than 50 percent. The average Type I error rate for a Type II error rate of 15 percent is 45.7 in the pre-1993 period, and in the post 1993 period the Type I error rate (for a Type II error rate of 15 percent) exceeds this for half of the years (1994, 1997-1998, and 2001-2003).

${ }^{50}$ In some years the predictive power of the FAST factors is better than the 1990 to 1992 period reported in Cummins, Grace and Phillips (1999), but overall there appears to be somewhat of a fall off in predictive power of the FAST factors in the post 1993 period compared to the pre 1993 period. For example, Type II error rates of more than 20 percent would be needed to achieve Type I error rates of less than 50 percent for 1997 to 1998 and 2003, but prior to 1993, Type II error rates of less than 10 percent would be needed to achieve Type I error rates of less than 50 percent.
} 
associated with Type I error rates of more than 40 percent in 5 of the eleven years from 1994 to 2004. Taken together, these results are consistent with the results in Table $5 .{ }^{51}$

\section{Robustness Tests}

Robustness tests were conducted with respect to the RBC and FAST Factor analysis in Tables 4 and 5. To reduce methodological bias, we conducted analysis using a sample of insolvent insurers for whom the first regulatory action was taken two or three years after the sample year. Thus for the sample of insolvent insurers used in these regressions for 1994, the insolvent insurer sample includes insurers for whom a first regulatory action was taken in 1996 or 1997. (Insurers becoming insolvent in 1995 are no longer included in this sample.) Overall, the trend in the results is consistent with what is reported in Tables 4 and 5.

Finally, we test the validity of the Type I/Type II error tradeoffs reported in Tables 4, 5 and 6 by also computing ECMs for a sample of representative years. More specifically, we calculate ECM for both sets of annual regressions in Tables 4 and 5 for 1994, 1997, 2000, and 2003 and for the model in Table 6. (See BarNiv (1990) and BarNiv and McDonald (1992) for an explanation of ECM.) We use a prior probability of insolvency of one percent. The misclassification costs for Type II errors are fixed at 1, while misclassification costs for Type I errors ranged from 1 to 200 .

The results indicate that the ECMs fluctuate over the sample years selected for the higher cost ratios. However, there are no substantial differences in ECMs across years for low values of the relative cost ratio. For example, when the relative cost ratio is set to 200, the ECM is 0.539 for the FAST model in 1997, and the ECM increases to 0.990 in 2003. The ECM has a high value in 1994 (i.e., 0.990 for the FAST model with the cost

\footnotetext{
${ }^{51}$ Results for the nonproportionate sample are available from an authors' appendix.
} 
ratio equal to 200). This is also consistent with the results of the Type I/Type II error tradeoffs for 1994. The ECM results for the RBC regressions have very similar patterns to the results reported in Table 4. Overall, the ECM results confirm the findings of the Type I/Type II error tradeoffs in Tables 4 and 5.

In computing ECMs for the model in Table 6, observations in the holdout sample are classified with cutoff values that minimize the ECM in the estimation sample for each relative cost of Type I error and Type II error. For relative cost ratios equal to 1, 5, 10, 20, 50, 100, 150, and 200, the ECMs of the estimation sample are 0.011, 0.051, 0.101, $0.198,0.389,0.541,0.663$, and 0.755 , respectively. The corresponding ECMs of the holdout sample are $0.011,0.051,0.101,0.201,0.312,0.446,0.520$, and 0.694 , respectively. Thus the ECM patterns are similar.

To make sure our pooled, nonproportionate sample in Table 6 is representative of the full sample of insurers available from the NAIC database, we estimated the model in Table 6 using the nonproportionate sample for the period 1994 to 1999 and using the full sample of insurers reporting to the NAIC for the period 1994 to 1999 . The regression results are very similar, suggesting that our data are representative. ${ }^{52}$

\section{Conclusion}

In response to a wave of insolvencies in the 1980s, the NAIC developed several mechanisms to reduce the occurrence of future insolvencies. Included in these mechanisms were the adoption of $\mathrm{RBC}$ requirements and the FAST system. The purpose of this research is to study how RBC and the components of the FAST system perform in contemporary insurer insolvency prediction in conjunction with other variables. Because the nature of insolvencies can vary over time, we posit that the ability of stable factors

\footnotetext{
${ }^{52}$ These results are available from an authors' appendix.
} 
such as the RBC ratio or a stable number of ratios used in the FAST system to predict insolvencies will decline over our sample period (1994 to 2008).

This research differs from prior research by looking at a new model, using data over a longer period of time and by analyzing post-implementation performance. New variables are included in the models that reflect the changing insurer marketplace such as exposure to hurricane prone areas and duration of the insurer's bond portfolio. This research innovates also by combining macroeconomic and industry-wide variables in the same prediction model with insurer specific variables.

Annual logistic regression results indicate that the overall accuracy in predicting insolvency of the RBC ratio or FAST financial ratios has not declined significantly over the sample period; instead their predictive ability fluctuates substantially from year to year. The latter suggests that the nature of insolvencies may change from one year to the next and/or that insurers are not gaming the $\mathrm{RBC}$ ratio (e.g., by making illusory changes or exploiting anomalies in the RBC formula). The results also indicate that the consistently used FAST financial ratios analyzed by Cummins, Grace, and Phillips (1999) tend to predict insolvencies better than the RBC ratio, but do not necessarily do so in every time period. The latter is not unexpected if factors relating to insolvencies change significantly over time.

In the pooled model, exposure to hurricane prone areas is significantly related to the chance of insolvency. In addition, macroeconomic and industry-wide factors are shown to be related to property-liability insurer insolvency propensity (i.e., the industrywide herfindahl index of premiums written, industry-wide combined ratio and changes in 
the interest rate). However, the Type I/Type II error tradeoff in the pooled model might be considered too large for the model to be useful in practice.

The finding of new, timely, variables related to insolvency such as hurricane exposure and the lack of complete reliability in previously relevant variables related to insolvency highlight the inherent difficulties in predicting insolvency. Currently, the U.S. solvency surveillance system is being evaluated/updated under the NAIC's Solvency Modernization Initiative. We believe that regulators as well as academics and insurers should find our results to be interesting in this updating/evaluation of the U.S. solvency surveillance system. 


\section{References}

A. M. Best Company, 1991, Best's Insolvency Study-Property/Casualty Insurers 19691990, Best's Review-Property/Casualty Insurance Edition, Auguest:16-23.

A. M. Best Company, miscellaneous years, Best's Insurance Reports Property/Casualty, (Oldwick, N.J.: A. M. Best).

Ambrose, J. M., and J. A. Seward, 1988, Best's Ratings, Financial Ratios and Prior Probabilities in Insolvency Prediction, Journal of Risk and Insurance 55, 229-244.

BarNiv, R., 1990, Accounting Procedures, Market Data, Cash-Flow Figures, and Insolvency Classification: The Case of the Insurance Industry, Accounting Review 65, 578-604.

BarNiv, R. and R. Hershbarger, 1990, Classifying Financial Distress in the Life Insurance Industry, Journal of Risk and Insurance 57, 110-136.

BarNiv, R. and J. McDonald, 1992, Identifying Financial Distress in the Insurance Industry: A Synthesis of Methodology and Empirical Issues, Journal of Risk and Insurance 54, 543-574.

BarNiv, R. and M. L. Smith, 1987, Underwriting Investment and Solvency, Journal of Insurance Regulation 5, 409-428.

Beaver, W. H., M. F. McNichols, and K. K. Nelson, 2003, Management of the Loss Reserve Accrual and the Distribution of Earnings in the Property-Casualty Insurance Industry, Journal of Accounting and Economics 35, 347-376.

Brockett, P. L., W. W. Cooper, L. L. Golden, and U. Pitaktong, 1994, A Neural Network Method for Obtaining an Early Warning of Insurer Insolvency, Journal of Risk and Insurance 61, 402-424.

Brockett, P. L., L. L. Golden, J. Jang, and C. Yang, 2006, A Comparison of Neural Network, Statistical Methods, and Variable Choice for Life Insurers' Financial Distress Prediction, Journal of Risk and Insurance 73, 397-419.

Browne, M. J., and R. E. Hoyt, 1995, Economic and Market Predictors of Insolvencies in the Property-Liability Insurance Industry, Journal of Risk and Insurance 62, 309-327.

Browne, M. J., J. M. Carson, and R. E. Hoyt, 1999, Economic and Market Predictors in the Life-Health Insurance Industry, Journal of Risk and Insurance 66, 643-659.

Chen, R., and K. A. Wong, 2004, The Determinants of Financial Health of Asian Insurance Companies, Journal of Risk and Insurance 71, 469-499. 
Cummins, J. D., 1991, Statistical and Financial Models of Insurance Pricing and the Insurance Firm, Journal of Risk and Insurance 58, 261-302.

Cummins, J. D., M. F. Grace and R. D. Phillips, 1999, Regulatory Solvency Prediction in Property-Liability Insurance: Risk-Based Capital, Audit Ratios, and Cash Flow Simulation, Journal of Risk and Insurance 66, 417-458.

Cummins, J. D., S. E. Harrington, and R. W. Klein, 1995, Insolvency Experience, RiskBased Capital, and Prompt Corrective Action in Property-Liability Insurance, Journal of Banking \& Finance 19, 511-527.

Flannery, M. J., 1981, Market Interest Rates and Commercial Bank Profitability: An Empirical Investigation, Journal of Finance 36, 1085-1101.

Flannery, M. J. and K. P. Rangan, 2004, What Caused the Bank Capital Build-up of the 1990s? FDIC Center for Financial Research Working Paper No. 2004-03

Furlong, F., 1988, Changes in Bank Risk-Taking, Federal Reserve Bank of San Francisco Economic Review, 45-56.

Gatev, E., and P. E. Strahan, 2006, Banks Advantage in Hedging Liquidity Risk: Theory and Evidence from the Commercial Paper Market, Journal of Finance 61, 867-892

Gaver, J. J., and J. S. Paterson, 2004, Do Insurers Manipulate Loss Reserves to Mask Solvency Problems? Journal of Accounting and Economics 37, 393-416.

Grace, M. F., S. E. Harrington, and R. W. Klein, 1998, Risk-Based Capital and Solvency Screening in Property-Liability Insurance: Hypothesis and Empirical Tests, Journal of Risk and Insurance 65, 213-243.

Grace, M. F., and J. L., Hotchkiss, 1995, External Impacts on the Property-Liability Insurance Cycle, Journal of Risk and Insurance 62, 738-754.

Greene, W. H., 2000, Econometric Analysis (Upper Saddle River, NJ: Prentice Hall).

Gron, A., 1994, Capacity Constraints and Cycles in Property-Casualty Insurance Markets, Rand Journal of Economics 25, 110-127.

Harrington, S. E., and J. M. Nelson, 1986, A Regression-Based Methodology for Solvency Surveillance in the Property-Liability Insurance Industry, Journal of Risk and Insurance 53, 583-605.

Kim, Y. D., D. R. Anderson, T. L. Amburgey, J. C. Hickman, 1995, The Use of Event History Analysis to Examine Insurer Insolvencies, Journal of Risk and Insurance 62, 94-110. 
Klein, R. W., 1995, Insurance Regulation in Transition, Journal of Risk and Insurance 62, 363-404.

Klein, R. W. and S. Wang, 2009. Catastrophe Risk Financing in the United States and the European Union: A Comparative Analysis of Alternative Regulatory Approaches, The Journal of Risk and Insurance 76(3), 607-637.

Lamm-Tennant, J., and Starks, L., 1993, Stock Versus Mutual Ownership Structures: the Risk Implications, Journal of Business 66, 29-46.

Lee, S. H., and J. L. Urrutia, 1996, Analysis and Prediction of Insolvency in the PropertyLiability Insurance Industry: A Comparison of Logit and Hazard Models, Journal of Risk and Insurance 63, 121-130.

Mayers, D. and C. W. Smith, Jr., 1981, Contractual Provisions, Organizational Structure, and Conflict Control in Insurance Markets, Journal of Business 54, 407-433.

Mayers, D. and C. W. Smith, Jr., 1988, Ownership Structure Across Lines of PropertyLiability Insurance, Journal of Law and Economics 31, 351-378.

Minton, B., A. B. Sanders and P. E. Strahan, 2004, Securitization by Banks and Finance Companies: Efficient Financial Contracting or Regulatory Arbitrage? Ohio State University and Boston College Working Paper, 2004

Palepu, K. G., 1986, Predicting Takeover Targets: A Methodological and Empirical Analysis, Journals of Accounting and Economics 8, 3-35.

Petroni, K. R., 1992, Optimistic Reporting in the Property-Casualty Insurance Industry, Journal of Accounting and Economics 15, 485-508.

Petroni, K. R., and M. Beasley, 1996, Errors in Accounting Estimates and Their Relation to Audit Firm Type, Journal of Accounting Research 34, 151-171.

Pregibon, D., 1981, Logistic Regresson Diagnostics, Annals of Statistics 9:705-727.

Sheldon, G., 1996, Capital Adequacy Rules and the Risk-Seeking Behavior of Banks: A Firm-Level Analysis, Swiss Journal of Economics and Statistics 132, 709-734.

Staking, K., and D. F. Babbel, 1995, The Relation Between Capital Structure, Interest Rate Sensitivity, and Market Value in the Property-Liability Insurance Industry, Journal of Risk and Insurance 62, 690-718.

Trieschmann, J. S., and G.. E. Pinches, 1973, A Multivariate Model for Predicting Financially Distressed Property-Liability Insurers, Journal of Risk and Insurance 40, 327-338. 
Winter, R. A., 1994, The Dynamics of Competitive Insurance Markets, Journal of Financial Intermediation 3, 379-415. 


\section{Appendix 1 \\ Nineteen FAST Ratio Results \\ 1994-2005}

\begin{tabular}{|c|c|c|c|c|c|}
\hline \multirow[b]{2}{*}{ Ratio } & \multicolumn{2}{|c|}{ Solvent $(\mathrm{n}=21620)$} & \multicolumn{2}{|c|}{ Insolvent $(\mathrm{n}=523)$} & \multirow{2}{*}{$\begin{array}{l}\text { Test } \\
\text { Statistic }\end{array}$} \\
\hline & Mean & Std. Dev & Mean & Std. Dev. & \\
\hline Receivables from Affiliates to Surplus & 0.026 & 0.073 & 0.062 & 0.127 & $* * *$ \\
\hline $\begin{array}{l}\text { Federal Income Tax Receivables and } \\
\text { Write-ins to Surplus Ratio }\end{array}$ & 0.021 & 0.037 & 0.029 & 0.055 & *** \\
\hline $\begin{array}{l}\text { Non-Investment Grade Bond Exposure } \\
\text { (Class 3-6) to Surplus Ratio }\end{array}$ & 0.047 & 0.174 & 0.041 & 0.134 & \\
\hline Other Invested Assets to Surplus Ratio & 0.022 & 0.064 & 0.036 & 0.093 & *** \\
\hline Change in Liquid Assets & 0.288 & 1.042 & 0.323 & 1.303 & \\
\hline Change in Agents' Balances & 0.292 & 2.242 & 0.160 & 2.733 & \\
\hline Gross Premiums to Surplus Ratio & 2.281 & 2.376 & 3.653 & 3.445 & *** \\
\hline Net Premiums Written to Surplus Ratio & 1.104 & 0.867 & 1.572 & 1.394 & $* * *$ \\
\hline Change in Gross Premiums Written & 0.154 & 0.624 & 0.132 & 0.757 & \\
\hline Change in Net Premiums Written & 0.156 & 0.708 & 0.150 & 1.028 & \\
\hline Surplus Aid to Surplus Ratio & 0.037 & 0.093 & 0.130 & 0.181 & $* * *$ \\
\hline $\begin{array}{l}\text { Reinsurance Recovered on Paid } \\
\text { Losses to Surplus Ratio }\end{array}$ & 0.662 & 1.263 & 1.384 & 1.998 & $* * *$ \\
\hline $\begin{array}{l}\text { Reinsurance Recovered on Unpaid } \\
\text { Losses to Surplus Ratio }\end{array}$ & 0.579 & 1.095 & 1.114 & 1.605 & $* * *$ \\
\hline Reserves to Surplus Ratio & 0.962 & 0.917 & 1.548 & 1.556 & **** \\
\hline $\begin{array}{l}\text { Net Premiums Written in Long-tailed } \\
\text { Lines to Net Premiums Written }\end{array}$ & 0.682 & 0.306 & 0.756 & 0.288 & *** \\
\hline $\begin{array}{l}\text { Cash Flow from Operations to } \\
\text { Premiums Collected Ratio }\end{array}$ & 0.156 & 2.004 & -0.130 & 3.157 & *** \\
\hline $\begin{array}{l}\text { Previous Year's Cash Flow from } \\
\text { Operations Ratio }\end{array}$ & 0.149 & 1.168 & 0.001 & 1.715 & ** \\
\hline Previous Year's Change in Surplus & 0.108 & 0.262 & 0.014 & 0.353 & *** \\
\hline Change in Combined Ratio & 0.028 & 0.39 & 0.14 & 0.549 & *** \\
\hline
\end{tabular}




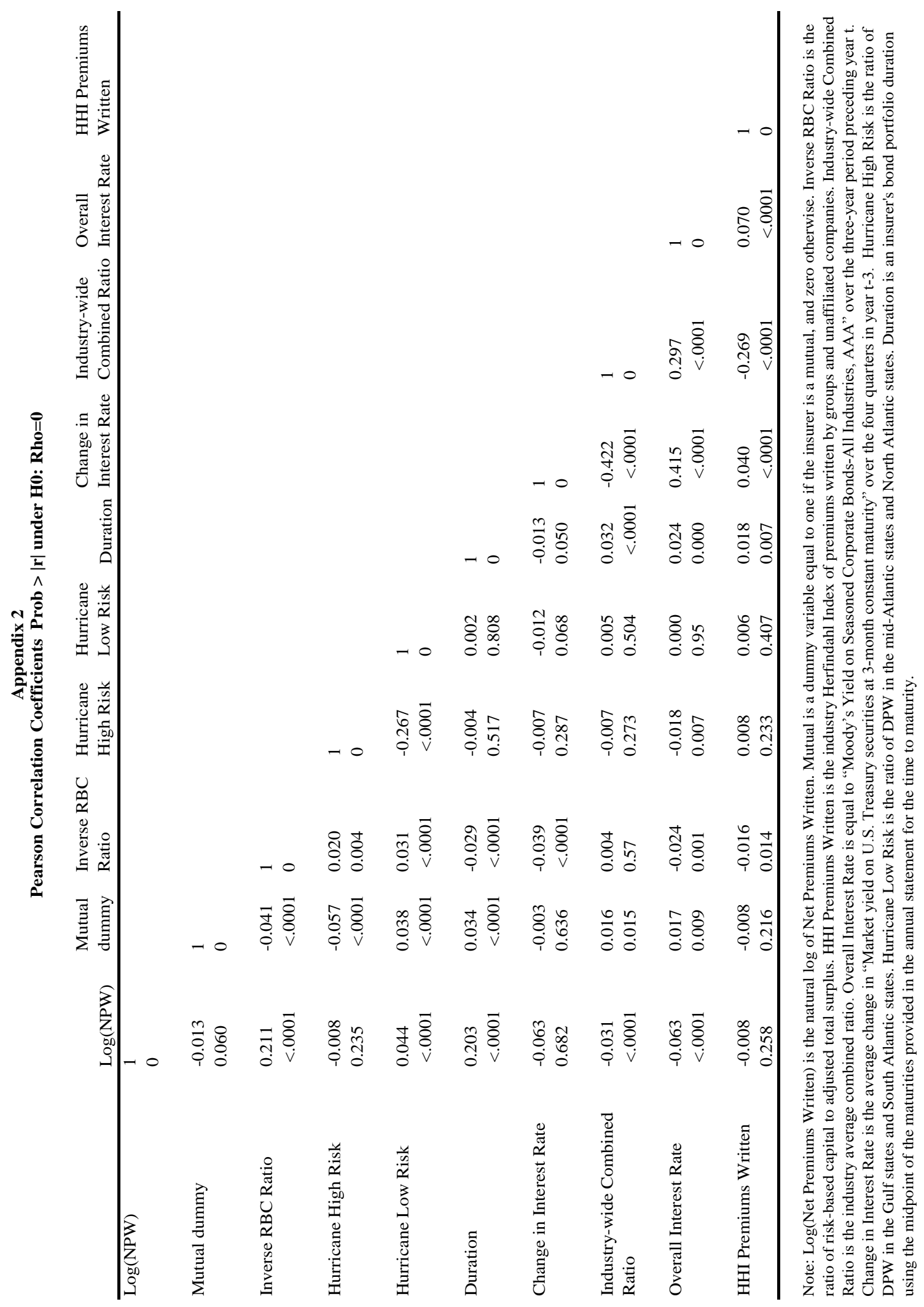


Table 1

Number of Solvent and Insolvent Insurers by Year

\begin{tabular}{ccccccc} 
& & No. of & No. of & Total No. of \\
Year (t) & Solvent sample & $\begin{array}{c}\text { Insolvencies in } \\
\mathrm{t}+1\end{array}$ & $\begin{array}{c}\text { No. of } \\
\text { Insolvencies in } \\
\mathrm{t}+2\end{array}$ & $\begin{array}{c}\text { No. of } \\
\text { Insolvencies in } \\
\mathrm{t}+3\end{array}$ & $\begin{array}{c}\text { Obs. for 3 Year } \\
\text { Insolvencies } \\
\text { from } \mathrm{t}+1 \text { to } \mathrm{t}+3\end{array}$ & $\begin{array}{c}\text { Prediction } \\
\text { Horizon }\end{array}$ \\
\hline 1994 & 1687 & 2 & 4 & 14 & 20 & 1707 \\
1995 & 1856 & 3 & 21 & 6 & 30 & 1886 \\
1996 & 1910 & 18 & 6 & 5 & 29 & 1939 \\
1997 & 1899 & 3 & 9 & 27 & 39 & 1938 \\
1998 & 1875 & 7 & 26 & 38 & 71 & 1946 \\
1999 & 1806 & 19 & 36 & 34 & 89 & 1895 \\
2000 & 1770 & 22 & 33 & 22 & 77 & 1847 \\
2001 & 1762 & 27 & 24 & 12 & 63 & 1825 \\
2002 & 1806 & 17 & 12 & 7 & 36 & 1842 \\
2003 & 1764 & 11 & 6 & 10 & 27 & 1791 \\
2004 & 1747 & 6 & 10 & 7 & 23 & 1770 \\
2005 & 1738 & 9 & 7 & 3 & 19 & 1757 \\
Total & 21620 & 144 & 194 & 185 & 523 & 22143 \\
\hline
\end{tabular}

Note: The number of insurers becoming insolvent from year $t+1$ to year $t+3$ is the number of insolvent insurers in the sample for the annual logistic regressions. The number of insolvent insurers used in the pooled analysis is the number of insurers that became insolvent in year $t+2$. 
Table 2

Summary Statistics for Solvent and Insolvent Insurers Using Three Year Prediction Horizon Sample Period: 1994 to 2005

\begin{tabular}{|c|c|c|c|c|}
\hline Variable & $\begin{array}{l}\text { Insolvent } \\
\text { Sample }\end{array}$ & & $\begin{array}{l}\text { Solvent } \\
\text { Sample }\end{array}$ & $\begin{array}{l}\text { Total } \\
\text { Sample }\end{array}$ \\
\hline Log(Net Premiums Written) & $16.261(456)$ & **** & $16.598(21620)$ & $16.591(22076)$ \\
\hline Mutual dummy & $0.096(523)$ & $* * *$ & $0.209(21620)$ & $0.207(22143)$ \\
\hline Inverse RBC Ratio & $0.320(523)$ & $* * *$ & $0.168(21620)$ & $0.171(22143)$ \\
\hline Hurricane High Risk & $0.295(523)$ & $* * *$ & $0.213(21594)$ & $0.214(22117)$ \\
\hline Hurricane Low Risk & $0.127(523)$ & $* * *$ & $0.094(21594)$ & $0.094(22117)$ \\
\hline Duration & $4.170(499)$ & $* * *$ & $5.241(21335)$ & $5.217(21834)$ \\
\hline Change in Interest Rate & $-0.163(519)$ & $* * *$ & $0.003(21620)$ & $-0.001(22139)$ \\
\hline Industry-wide Combined Ratio & $105.962(519)$ & $* * *$ & $104.637(21620)$ & $104.668(22139)$ \\
\hline Overall Interest Rate & $5.007(519)$ & $* * *$ & $4.808(21620)$ & $4.813(22139)$ \\
\hline HHI Premiums Written & $3.478(519)$ & **** & $3.388(21620)$ & $3.400(22139)$ \\
\hline
\end{tabular}

Note: Number of observations is in parentheses. T-tests are run between solvent and insolvent firms. Three year prediction horizon used for insolvent firms. *** significant at 1 percent level, ** significant at 5 percent level, and * significant at 10 percent level.

Note: $\log$ (Net Premiums Written) is the natural log of Net Premiums Written. Mutual is a dummy variable equal to one if the insurer is a mutual, and zero otherwise. Inverse RBC Ratio is the ratio of risk-based capital to adjusted total surplus. HHI Premiums Written is the industry Herfindahl Index of premiums written by groups and unaffiliated companies. Industry-wide Combined Ratio is the industry average combined ratio. Overall Interest Rate is equal to "Moody's Yield on Seasoned Corporate Bonds-All Industries, AAA" over the three-year period preceding year t. Change in Interest Rate is the average change in "Market yield on U.S. Treasury securities at 3-month constant maturity" over the four quarters in year t3. Hurricane High Risk is the ratio of DPW in the Gulf states and South Atlantic states. Hurricane Low Risk is the ratio of DPW in the mid-Atlantic states and North Atlantic states. Duration is an insurer's bond portfolio duration using the midpoint of the maturities provided for the time to maturity. 


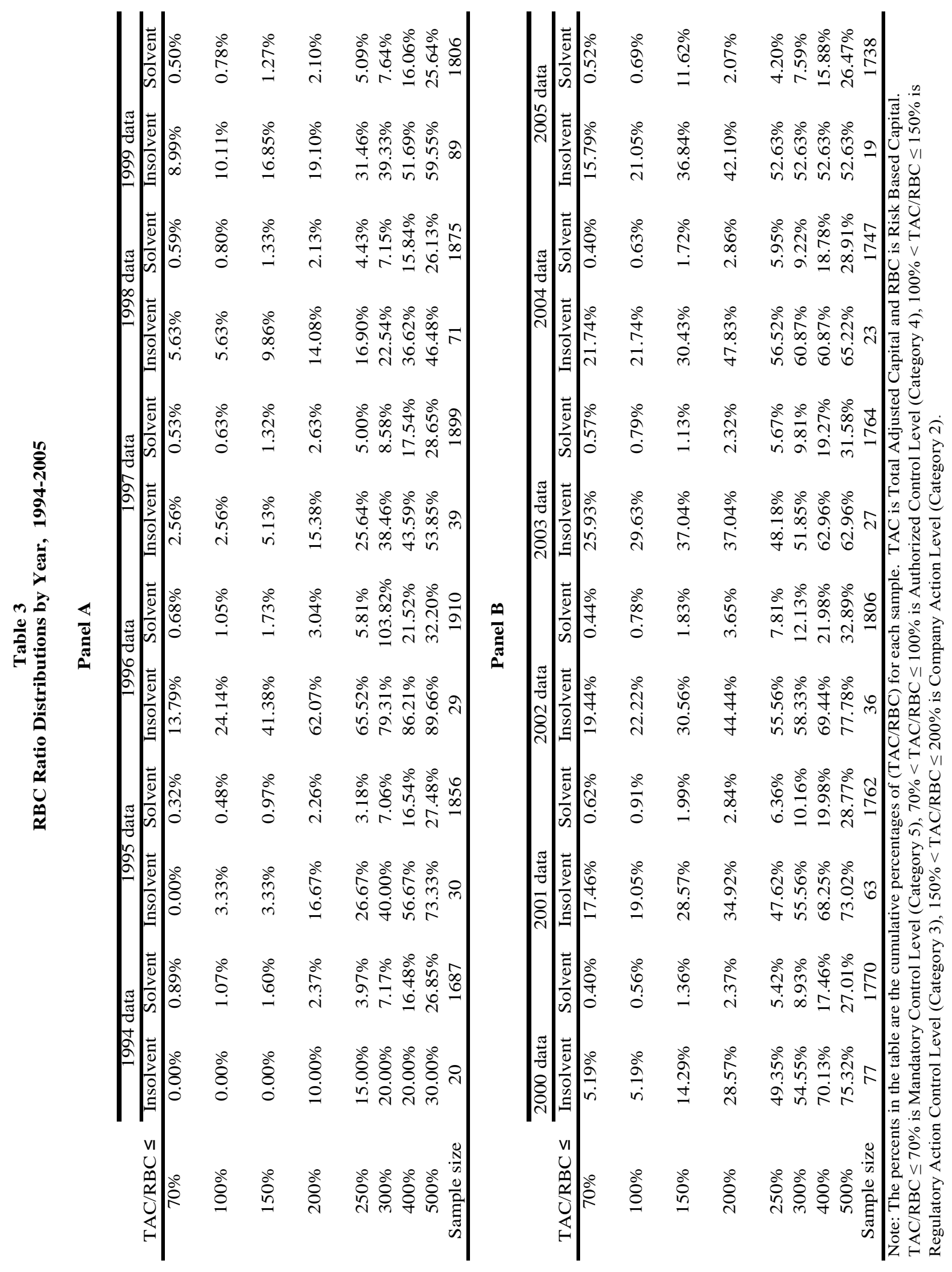




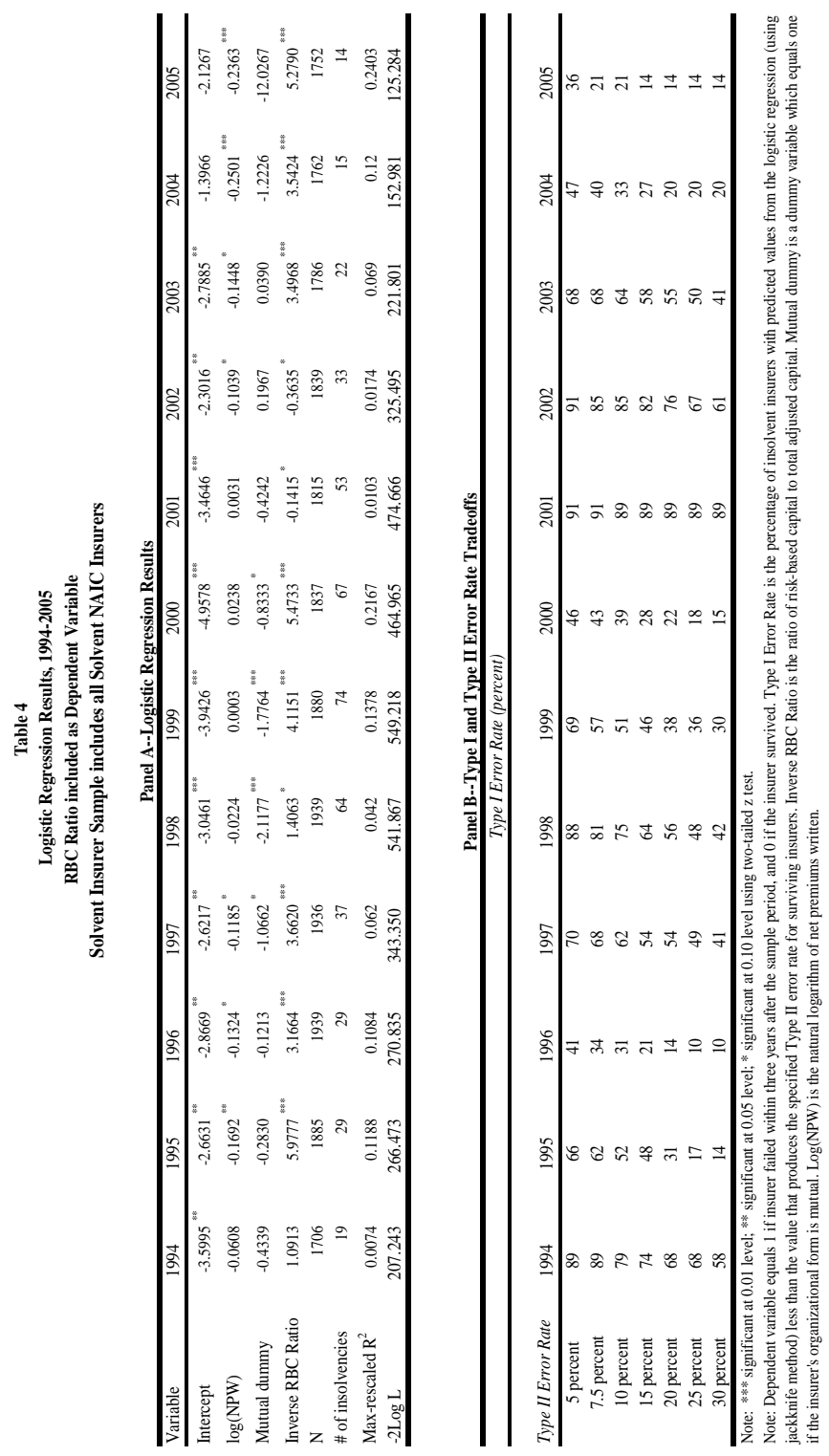




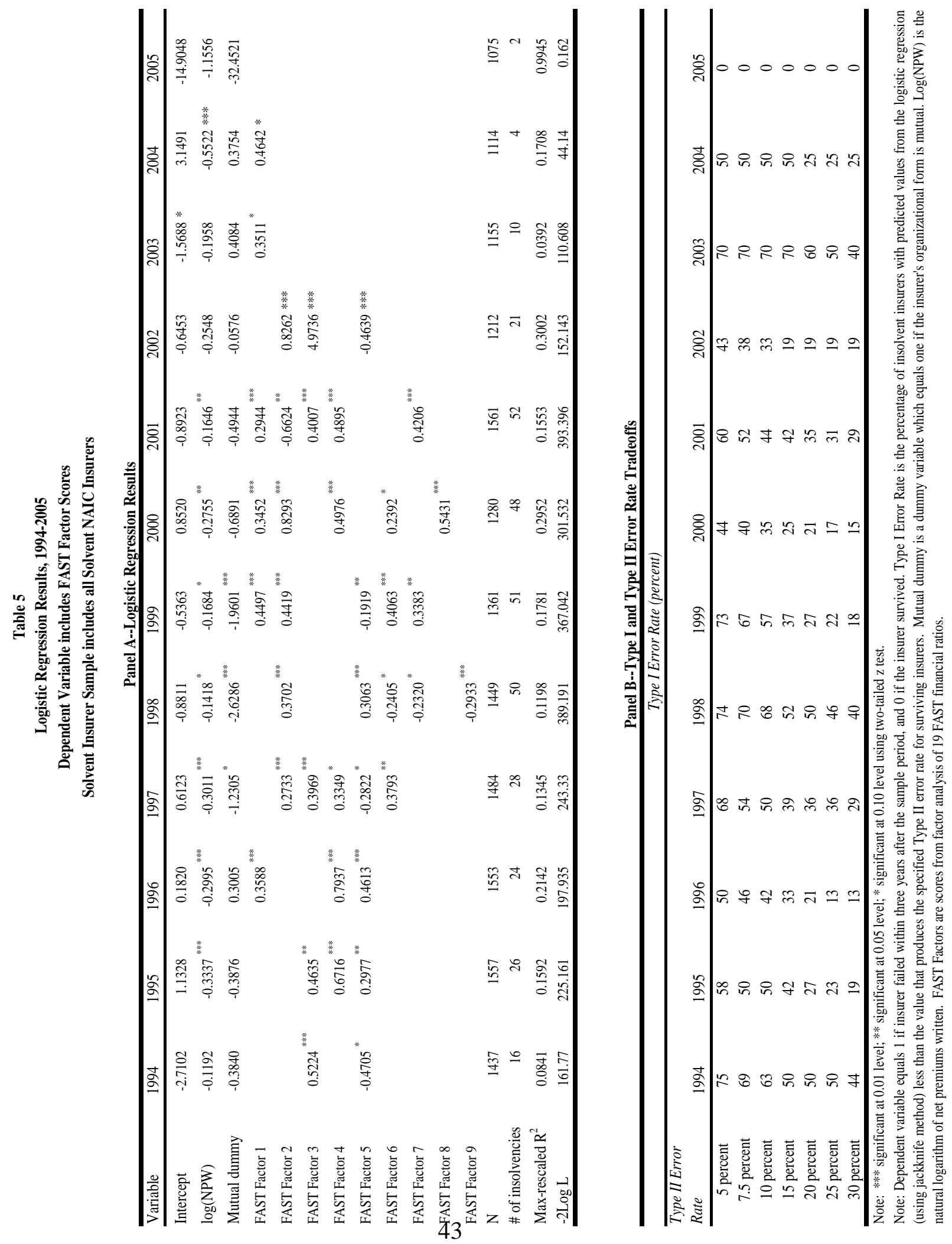


Table 6

Logistic Pooled Regression Results

Dependent Variable: Insolvent in $\mathrm{t}+2$ Years

Nonproportionate Sample, 1990-1992, 1994-1999

\begin{tabular}{|c|c|c|}
\hline \multicolumn{3}{|c|}{ Panel A } \\
\hline Variable & Estimate & Std. Err \\
\hline Intercept & -16.107 & $6.90^{* *}$ \\
\hline $\log (\mathrm{NPW})$ & -0.236 & $0.05^{* * * *}$ \\
\hline Mutual dummy & -1.047 & $0.33^{* * *}$ \\
\hline Inverse RBC Ratio & 1.972 & $0.44^{* * * *}$ \\
\hline Cons. Factor 1 & 0.174 & $0.10^{*}$ \\
\hline Cons. Factor 2 & 0.218 & $0.10^{* *}$ \\
\hline Cons. Factor 3 & 0.202 & $0.09^{* * *}$ \\
\hline Hurricane High Risk & 0.628 & $0.27^{* *}$ \\
\hline Hurricane Low Risk & 0.456 & 0.44 \\
\hline Duration & -0.002 & 0.03 \\
\hline Industry-wide Combined Ratio & 0.123 & $0.05^{* *}$ \\
\hline HHI Premiums Written & 0.919 & $0.38^{* *}$ \\
\hline Change in Interest Rate & 0.298 & $0.14^{* *}$ \\
\hline Overall Interest Rate & 0.098 & 0.15 \\
\hline $\mathrm{N}$ & 2089 & \\
\hline \# of insolvencies & 119 & \\
\hline R-Square & 0.047 & \\
\hline Max-rescaled R-Square & 0.136 & \\
\hline$-2 \log L$ & 821.53 & \\
\hline
\end{tabular}

Panel B

\begin{tabular}{ccc}
\hline & Type I Error Rate (\%) & \\
\hline Type II Error Rate & 1991-99 Sample & Holdout Sample 2000-05 \\
\hline 5 percent & 76 & 72 \\
7.5 percent & 67 & 51 \\
10 percent & 58 & 43 \\
15 percent & 48 & 32 \\
20 percent & 39 & 17 \\
25 percent & 32 & 15 \\
30 percent & 24 & 15 \\
\hline
\end{tabular}

Note: Holdout sample has 1225 solvent firms and 47 insolvent firms for years 2000-2005. Dependent variable equals 1 if insurer failed in year $t+2$, and zero otherwise. Type I Error Rate is the percentage of insolvent insurers with predicted value from the logistic regression (using jackknife method) less than the value that produces the specified Type II error rate for surviving insurers within two years. *** significant at 0.01 level; ** significant at 0.05 level; * significant at 0.10 level. Note: $\log ($ Net Premiums Written) is the natural log of Net Premiums Written. Mutual dummy is equal to one if the insurer is a mutual, and zero otherwise. Inverse RBC Ratio is the ratio of risk-based capital to adjusted total surplus. HHI Premiums Written is the industry Herfindahl Index of premiums written by groups and unaffiliated companies. Industry-wide Combined Ratio is the industry average combined ratio. Overall Interest Rate is equal to "Moody's Yield on Seasoned Corporate Bonds-All Industries, AAA" over the two-year period preceding year t. Change in Interest Rate is the average change in "Market yield on U.S. Treasury securities at 3-month constant maturity" over the four quarters in year t-2. Hurricane High Risk is the ratio of DPW in the Gulf states and South Atlantic states. Hurricane Low Risk is the ratio of DPW in the mid-Atlantic states and North Atlantic states. Duration is an insurer's bond portfolio duration using the midpoint of the maturities provided in the annual statement for the time tofuaturity. FAST Factors are scores from factor analysis of 19 FAST financial ratios. 